\title{
Clinicopathologic significance of TROP2 and phospho-TROP2 in gastric cancer
}

\author{
SHUHEI KUSHIYAMA $^{1-3}$, MASAKAZU YASHIRO ${ }^{1-3}$, YURIE YAMAMOTO ${ }^{2,3}$, TOMOHIRO SERA ${ }^{1-3}$, \\ ATSUSHI SUGIMOTO ${ }^{1-3}$, SADAAKI NISHIMURA ${ }^{1-3}$, SHINGO TOGANO ${ }^{1-3}$, KENJI KURODA $^{1-3}$, \\ MAMI YOSHII $^{1}$, TATSURO TAMURA ${ }^{1}$, TAKAHIRO TOYOKAWA ${ }^{1}$, HIROAKI TANAKA ${ }^{1}$, \\ KAZUYA MUGURUMA $^{1}$, HIROSHI NAKADA ${ }^{4}$ and MASAICHI OHIRA ${ }^{1}$ \\ Departments of ${ }^{1}$ Gastroenterological Surgery, and ${ }^{2}$ Molecular Oncology and Therapeutics, \\ ${ }^{3}$ Cancer Center for Translational Research, Osaka City University Graduate School of Medicine, Osaka 545-8585; \\ ${ }^{4}$ Department of Molecular Biosciences, Faculty of Life Science, Kyoto Sangyo University, Kyoto 603-8555, Japan
}

Received August 28, 2020; Accepted January 19, 2021

DOI: $10.3892 / \operatorname{mco} .2021 .2267$

\begin{abstract}
Trophoblast cell-surface antigen 2 (TROP2) is a transmembrane glycoprotein expressed in epithelial cells Increased TROP2 expression has been reported to be associated with malignant progression in most carcinomas; however, TROP2 has a tumor-suppressive function in certain types of cancer. Since the function of TROP2 is controversial, the present study subsequently aimed to clarify the clinicopathologic significance of TROP 2 and pTROP 2 expression in human gastric cancer (GC). The cases of 704 patients with GC who underwent gastrectomy were retrospectively analyzed. The expression levels of TROP2 and pTROP2 in each tumor were evaluated by immunohistochemistry. The association between the clinicopathologic features of patients with GC and the levels of TROP2 and pTROP2 in their tumors was analyzed. Increased TROP 2 and pTROP 2 expression was identified in $330(46.9 \%)$ and $306(43.5 \%)$ of the 704 patients with GC, respectively. Increased TROP2 expression was associated with the histological intestinal type, high tumor invasion depth (T3/T4), lymph node metastasis, lymphatic invasion and venous invasion. By contrast, increased pTROP2 expression was associated with intestinal type, low tumor invasion
\end{abstract}

Correspondence to: Dr Masakazu Yashiro, Department of Molecular Oncology and Therapeutics, Osaka City University Graduate School of Medicine, 1-4-3 Asahimachi, Abeno-ku, Osaka 545-8585, Japan

E-mail:m9312510@med.osaka-cu.ac.jp

Abbreviations: TROP2, trophoblast cell-surface antigen 2; pTROP2, phospho-trophoblast cell-surface antigen 2; GC, gastric cancer; TACSTD2, tumor-associated calcium signal transducer 2; PKC, protein kinase C; PIP2, phosphatidylinositol 4,5-bisphosphate; IGF1, insulin-like growth factor 1; IGF1R, insulin-like growth factor 1 receptor; KLH, Keyhole limpet hemocyanin; OS, overall survival

Key words: TROP2, pTROP2, gastric cancer, clinicopathologic feature, immunohistochemistry depth (T1/2), no lymph node metastasis and no lymphatic invasion. Increased TROP 2 expression was associated with poorer overall survival (OS) $(\mathrm{P}<0.01$; log rank test), whereas increased pTROP2 expression was significantly associated with improved OS $(\mathrm{P}<0.01 ; \log$ rank test). In conclusion, increased expression levels of TROP2, but not pTROP2, may be associated with the metastatic ability of GC, resulting in poor prognosis of patients with GC.

\section{Introduction}

There have been recent advances in the diagnostic and therapeutic techniques for gastric cancer (GC), but GC remains as the third leading cause of cancer mortality worldwide (1). Although adjuvant treatment has prolonged the survival of GC patients, the overall survival (OS) after surgery for GC remains poor $(2,3)$.

Trophoblast cell-surface antigen 2 (TROP2) encoded by tumor-associated calcium signal transducer 2 (TACSTD2) gene is a transmembrane glycoprotein expressed in epithelial cells (4). TROP2 was identified in human trophoblast and choriocarcinoma cell lines (5). TROP2 was reported to bind to claudin1, claudin7, cyclin D1, protein kinase C (PKC), phosphatidylinositol 4,5-bisphosphate (PIP2), and insulin-like growth factor 1 (IGF1) (5-7). It is suspected that by its binding to these proteins, TROP2 might affect the tight junctions of epithelial cells (8), tumor proliferation (9), podosome formation, Raf and $\mathrm{NF}-\kappa \mathrm{B}$ activation $(5,8)$, and IGF1 receptor (IGF1R) suppression (10).

The expression of TROP2 was described in several studies as being associated with the invasion and metastasis of cancer cells, resulting in poor prognoses of GC, pancreatic cancer, oral cancer, colon cancer, and ovarian carcinoma (11-16). However, TROP2 was reported to have a tumor-suppressive function in cervical cancer, lung adenocarcinoma, and head and neck squamous cell cancer $(10,17,18)$. The functions of TROP2 are thus a matter of controversy. Phosphorylation of proteins on cell membrane is important in considering intracellular signals, but there are few reports on phospho-TROP2 (pTROP2). In addition, there is no report about the clinicopathologic significance 
of pTROP2. We conducted the present study to clarify the clinicopathologic significance of TROP2 and pTROP2 in GC. This study is the first to reveal the correlation between the GC patients' clinicopathologic features and the TROP 2 and pTROP2 expression in their tumors.

\section{Materials and methods}

Patients. A total of 704 patients who were histologically confirmed to have primary GC and underwent a resection of gastric tumor and regional lymph nodes at Osaka City University Hospital between 1997 and 2006 were enrolled in this study. None of patients had undergone preoperative radiation and/ or chemotherapy. The pathologic diagnoses and classifications were made according to the UICC TNM classification of malignant tumors. This study was approved by Osaka City University ethics committee (reference number, 924). Informed consent was obtained in writing from all patients.

Immunohistochemistry of TROP 2 and $P T R O P 2$. The expression of TROP2 and pTROP2 were evaluated by immunohistochemistry. The immunohistochemical determination of them were examined as the manufacturer's instructions. Briefly, Slides were deparaffinized and rehydrated with xylene and graded alcohol series and activated by heating. Endogenous peroxidase was blocked and then sections were incubated with an anti-mouse antibody for TROP2 (1:250, sc-376746, Santa Cruz Biotechnology) or anti-rabbit antibody for pTROP2 (1:200, obtained from Kyoto Sangyo University). Anti-rabbit antibody for pTROP2 was produced by the following method. Keyhole limpet hemocyanin (KLH)-conjugated peptides (Trop-2 cytoplasmic domain) with phosphorylated Ser-322 were emulsified with Freund's complete (first time) and incomplete (from second time) adjuvant and injected subcutaneously five times into a 12-week-old female New Zealand white rabbit (19). After the fifth immunization, blood was taken, and an IgG fraction was prepared from the serum by protein A-Sepharose column chromatography. The sections were incubated with biotinylated second antibody. They were treated with streptavidin-peroxidase reagent and counterstained with Mayer's hematoxylin. TROP2 expression was evaluated by intensity of staining and percentage of stained tumor cells. Intensity was given scores $0-3$ ( 0 , no; 1 , weak; 2 , moderate; 3 , strong) and the percentage of stained tumor cells in all tumor cells was given scores $0-3(0=0 \%, 1=1 \%-30 \%, 2=31 \%-70 \%, 3=71 \%-100 \%)$. The two scores were multiplied to obtain the final score of 0-9. TROP 2 positive was defined as the score was $\geq 3$. pTROP2 expression was evaluated by intensity of staining of tumor cells and was given scores 0-3 like TROP2. pTROP2-positive was defined as the intensity score was $\geq 1$.

Statistical analysis. Statistical analysis was performed by R for Windows OS (version 3. 5. 2). The association between TROP2 or pTROP2 expression and clinicopathological variables were assessed by the chi-square test. Survival was measured from the date of surgery. OS was analyzed by Kaplan-Meier method and compared by log-rank test. The Cox proportional hazards model was used for univariate analysis and multivariate analysis. A P-value $<0.05$ was considered to indicate a statistically significant difference.

\section{Results}

Immunostaining findings of TROP2 and pTROP2. Fig. 1 provides representative immunostaining patterns of TROP2 and pTROP2. TROP2 and pTROP2 were stained at the cytoplasm and the cell membrane of cancer cells. TROP2 was expressed mainly at the cell membrane, whereas pTROP2 was expressed mainly at the cell cytoplasm. Of the total of 704 cases, $330(46.9 \%)$ were TROP2-positive and 306 (43.5\%) were pTROP2-positive. TROP2 expression was found on stromal cells in normal gastric tissue but not on mucosa. In contrast, neither stromal cells nor mucosa did not express pTROP2 in normal gastric tissue (Fig. 1C and F).

Expression levels of TROP 2 and pTROP 2 and their correlations with clinicopathological features. The clinicopathological features of all 704 patients based on the TROP2 and pTROP 2 expression in their cancer cells are summarized in Table I. Compared to TROP2 negativity of cancer cells, TROP2 positivity of cancer cells was significantly associated with age $>60$ years $(\mathrm{P}<0.01)$, male gender $(\mathrm{P}<0.01)$, differentiated type $(\mathrm{P}<0.01)$, tumor depth $(\mathrm{T} 3 / \mathrm{T} 4)(\mathrm{P}<0.01)$, lymph node metastasis $(\mathrm{P}<0.01)$, lymphatic invasion $(\mathrm{P}<0.01)$, venous invasion $(\mathrm{P}<0.01)$, pTROP2 overexpression $(\mathrm{P}<0.01)$. The overexpression of pTROP2 was significantly correlated with differentiated type $(\mathrm{P}<0.01)$, tumor depth $(\mathrm{T} 1 / \mathrm{T} 2)(\mathrm{P}<0.01)$, no lymph node metastasis $(\mathrm{P}<0.01)$, and no lymphatic invasion $(\mathrm{P}<0.01)$.

Survival. The 5-year OS rate of the 330 patients in the TROP2-positive group was significantly poorer compared to that of the TROP2-negative group ( $\mathrm{P}<0.01$, Fig. $2 \mathrm{~A})$. The 5-year OS rate of the patients in the pTROP2-positive group was significantly better compared to that of the pTROP2-negative patients $(\mathrm{P}<0.01$, Fig. $2 \mathrm{~B})$. Our analysis by each tumor stage revealed that there was no significant difference in OS between the TROP2-positive and TROP2-negative cases at each tumor stage. The OS of the pTROP2-positive cases was not significantly different from that of the pTROP2-negative cases at each stage. OS of the 4 groups divided by the expression of TROP2 and pTROP2 was analyzed by Kaplan-Meier method and compared by log-rank test in Fig. 3. A subgroup analysis of OS significantly showed that patients with TROP2 (-)/pTROP2 (+) had a good prognosis, but patients with TROP2 (+)/pTROP2 (-) had a poor prognosis $(\mathrm{P}<0.01)$. Comparing by TROP2 expression, pTROP2 expression did not affect the prognosis in the case of TROP2 negative ( $\mathrm{P}=0.112)$, but patients with pTROP2 overexpression had significantly better prognosis in the case of TROP2-positive $(\mathrm{P}<0.01)$.

Univariate and multivariate analyses. The results of the univariate and multivariate analyses for OS are given in Table II. The univariate analysis showed that poor OS was significantly correlated with undifferentiated type $(\mathrm{P}<0.01)$, depth of tumor $(\mathrm{T} 3$ and $\mathrm{T} 4)(\mathrm{P}<0.01)$, lymph node metastasis $(\mathrm{P}<0.01)$, distant metastasis $(\mathrm{P}<0.01)$, venous invasion $(\mathrm{P}<0.01)$, lymphatic invasion $(\mathrm{P}<0.01)$, TROP2 overexpression $(\mathrm{P}<0.01)$, and $\mathrm{pTROP} 2$ overexpression $(\mathrm{P}<0.01)$. There was no significant difference in age and sex in univariate analysis. Since univariate analysis showed a 
A

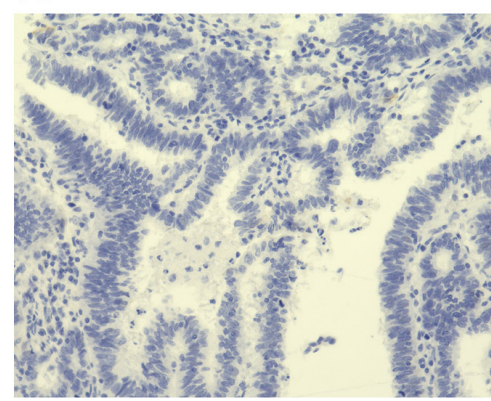

D

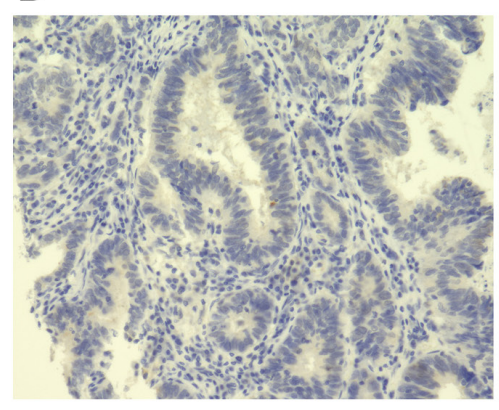

B

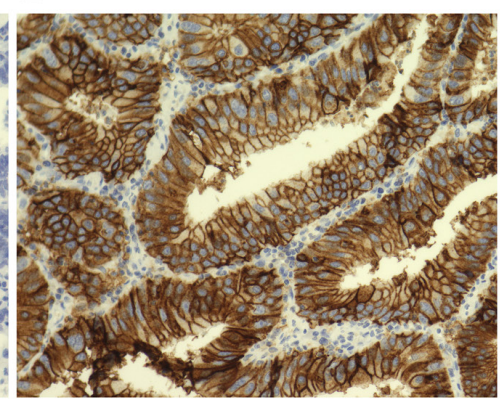

C

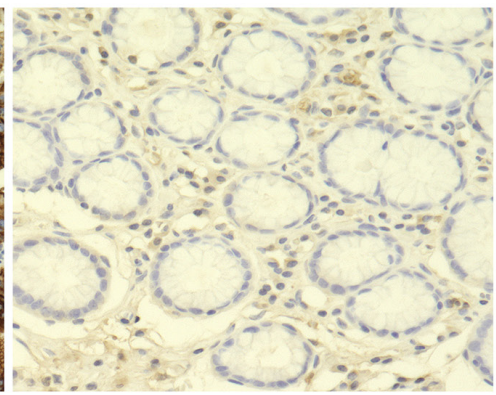

F

E

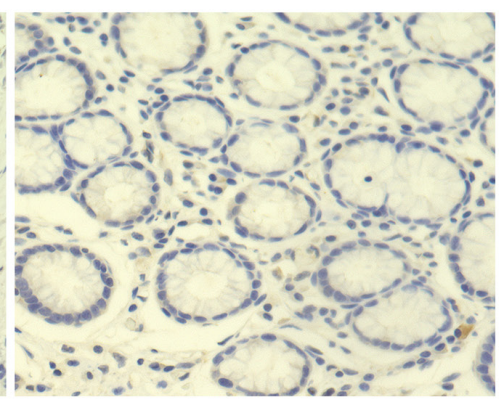

Figure 1. Representative images of TROP2 and pTROP2 expression in gastric cancer. TROP2 was expressed mainly at the cell membrane. pTROP2 was expressed mainly at the cell cytoplasm. (A) A TROP2-negative case. (B) A TROP2-positive case. (C) Typical TROP2 immunostaining image of normal gastric mucosa. (D) A pTROP2-negative case. (E) A pTROP2-positive case. (F) Typical pTROP2 immunostaining image of normal gastric mucosa. Magnification, x200. TROP2, trophoblast cell-surface antigen 2; pTROP2, phospho-trophoblast cell-surface antigen 2.

A

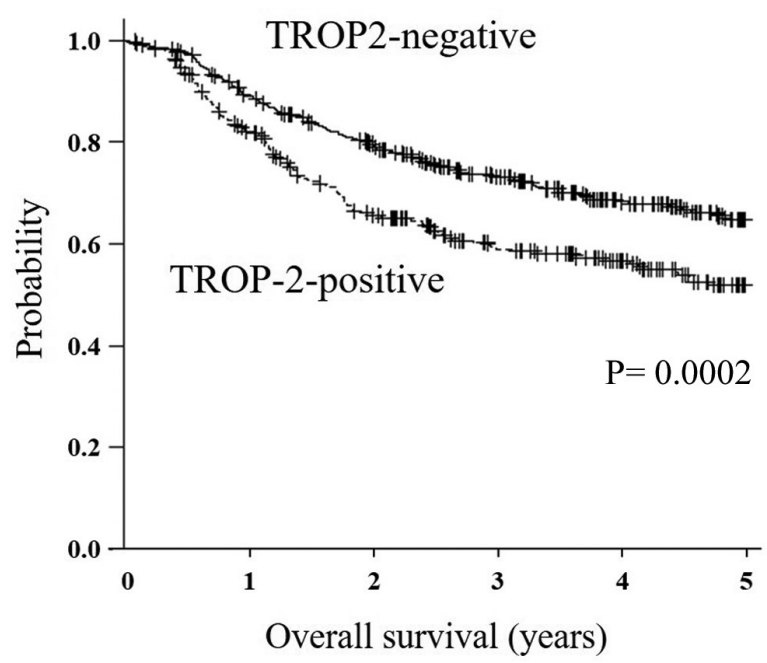

$\mathrm{B}$

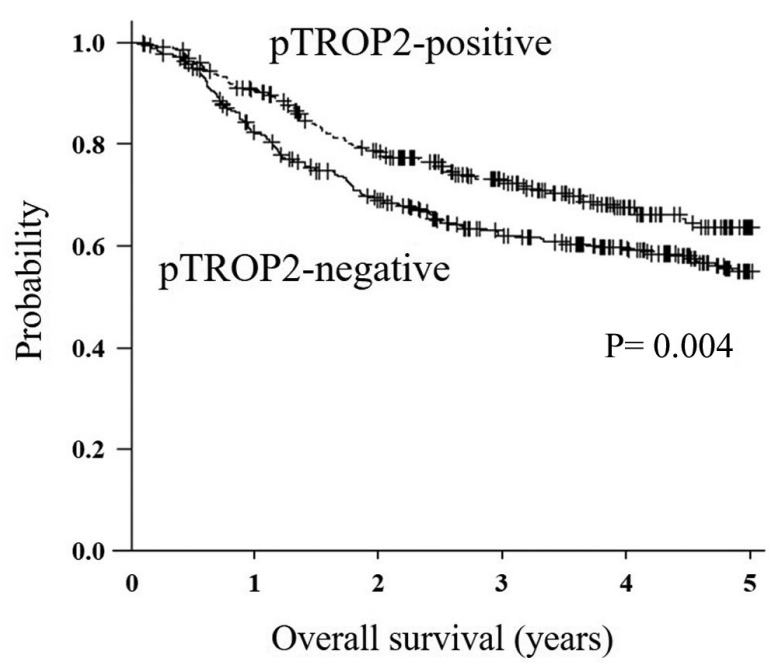

Figure 2. OS of patients with gastric cancer based on TROP2 or pTROP2 expression. (A) Kaplan-Meier survival curve indicating that the OS of all TROP2-positive patients was significantly worse than that of the TROP2-negative patients $(\mathrm{P}<0.01)$. (B) Kaplan-Meier survival curve indicating that the OS of all pTROP2-negative patients in cancer cells was significantly worse than that of the pTROP2-positive patients $(\mathrm{P}<0.01)$. OS, overall survival; TROP2, trophoblast cell-surface antigen 2; pTROP2, phospho-trophoblast cell-surface antigen 2.

correlation between TROP 2 and pTROP2 and they could be confounding factors, multivariate analysis was performed using either TROP2 or pTROP2 and the significant factors of univariate analysis. The multivariate analysis including TROP2 revealed that undifferentiated type $(\mathrm{P}<0.05)$, depth of tumor $(\mathrm{P}<0.01)$, lymph node metastasis $(\mathrm{P}<0.01)$, and distant metastasis $(\mathrm{P}<0.01)$ were significantly correlated with poorer OS. TROP2 and lymphatic invasion were not significantly associated with OS. The multivariate analysis including pTROP2 revealed that depth of tumor $(\mathrm{P}<0.01)$, lymph node metastasis $(\mathrm{P}<0.01)$, distant metastasis $(\mathrm{P}<0.01)$, and lymphatic invasion $(\mathrm{P}<0.05)$ were significantly associated with poorer OS. pTROP2 and microscopic type were not significantly associated with OS. In both multivariate analyses, TROP2 and pTROP2 were not significantly associated with poorer OS. 
Table I. Association between the levels of TROP2 and pTROP2 in tumour cells and clinicopathologic features in 704 patients with gastric cancer.

\begin{tabular}{|c|c|c|c|c|c|c|}
\hline \multirow[b]{2}{*}{$\begin{array}{l}\text { Clinicopathologic } \\
\text { features }\end{array}$} & \multicolumn{2}{|c|}{ TROP2 } & \multirow[b]{2}{*}{ P-value } & \multicolumn{2}{|c|}{ pTROP2 } & \multirow[b]{2}{*}{ P-value } \\
\hline & $\begin{array}{l}\text { Negative, } \mathrm{n} \\
(\% ; \mathrm{n}=374)\end{array}$ & $\begin{array}{l}\text { Positive, } \mathrm{n} \\
(\% ; \mathrm{n}=330)\end{array}$ & & $\begin{array}{l}\text { Negative, } \mathrm{n} \\
(\% ; \mathrm{n}=398)\end{array}$ & $\begin{array}{l}\text { Positive, } \mathrm{n} \\
(\% ; \mathrm{n}=306)\end{array}$ & \\
\hline \multicolumn{7}{|l|}{ Age, years } \\
\hline$<60$ & $134(63.51)$ & $77(36.49)$ & \multirow[t]{2}{*}{0.0003} & $120(56.87)$ & $91(43.13)$ & \multirow[t]{2}{*}{0.9058} \\
\hline$\geq 60$ & $240(48.68)$ & $253(51.32)$ & & $278(56.39)$ & $215(43.61)$ & \\
\hline \multicolumn{7}{|l|}{ Sex } \\
\hline Female & $183(59.22)$ & $126(40.78)$ & \multirow[t]{2}{*}{0.0041} & $176(56.96)$ & $133(43.04)$ & \multirow[t]{2}{*}{0.8410} \\
\hline Male & $191(48.35)$ & $204(51.65)$ & & $222(56.20)$ & $173(43.80)$ & \\
\hline \multicolumn{7}{|l|}{ Microscopic type } \\
\hline Differentiated & $133(41.82)$ & $185(58.18)$ & \multirow[t]{2}{*}{$<0.0001$} & $147(46.23)$ & $171(53.77)$ & \multirow[t]{2}{*}{$<0.0001$} \\
\hline Undifferentiated & $241(62.44)$ & 145 (37.56) & & $251(65.03)$ & 135 (34.97) & \\
\hline \multicolumn{7}{|l|}{ Tumor depth } \\
\hline $\mathrm{T} 1, \mathrm{~T} 2$ & $207(60.00)$ & $138(40.00)$ & \multirow[t]{2}{*}{0.0003} & $173(50.14)$ & $172(49.86)$ & \multirow[t]{2}{*}{0.0008} \\
\hline $\mathrm{T} 3, \mathrm{~T} 4$ & $167(46.52)$ & $192(53.48)$ & & 225 (62.67) & $134(37.33)$ & \\
\hline \multicolumn{7}{|c|}{ Lymph node metastasis } \\
\hline Negative & $225(63.03)$ & $132(36.97)$ & \multirow[t]{2}{*}{$<0.0001$} & $184(51.54)$ & $173(48.46)$ & \multirow[t]{2}{*}{0.0078} \\
\hline Positive & $146(42.57)$ & $197(57.43)$ & & $211(61.52)$ & $132(38.48)$ & \\
\hline \multicolumn{7}{|l|}{ Lymphatic invasion } \\
\hline Negative & $181(65.58)$ & $95(34.42)$ & \multirow[t]{2}{*}{$<0.0001$} & $140(50.72)$ & $136(49.28)$ & \multirow[t]{2}{*}{0.0113} \\
\hline Positive & $193(45.20)$ & $234(54.80)$ & & $258(60.42)$ & $169(39.58)$ & \\
\hline \multicolumn{7}{|l|}{ Venous invasion } \\
\hline Negative & $330(58.51)$ & 234 (41.49) & \multirow[t]{2}{*}{$<0.0001$} & $316(56.03)$ & 248 (43.97) & \multirow[t]{2}{*}{0.5869} \\
\hline Positive & $44(31.43)$ & 96 (68.57) & & $82(58.57)$ & $58(41.43)$ & \\
\hline \multicolumn{7}{|l|}{ Distant metastasis } \\
\hline Negative & $358(53.19)$ & $315(46.81)$ & \multirow[t]{2}{*}{0.9881} & $380(56.46)$ & $293(43.54)$ & \multirow[t]{2}{*}{0.7022} \\
\hline Positive & $16(53.33)$ & 14 (46.67) & & $18(60.00)$ & $12(40.00)$ & \\
\hline \multicolumn{7}{|l|}{ pTROP2 } \\
\hline Negative & $243(61.06)$ & $155(38.94)$ & \multirow[t]{2}{*}{$<0.0001$} & & & \\
\hline Positive & $131(42.81)$ & 175 (57.19) & & & & \\
\hline
\end{tabular}

TROP2, trophoblast cell-surface antigen 2; pTROP2, phospho-trophoblast cell-surface antigen 2.

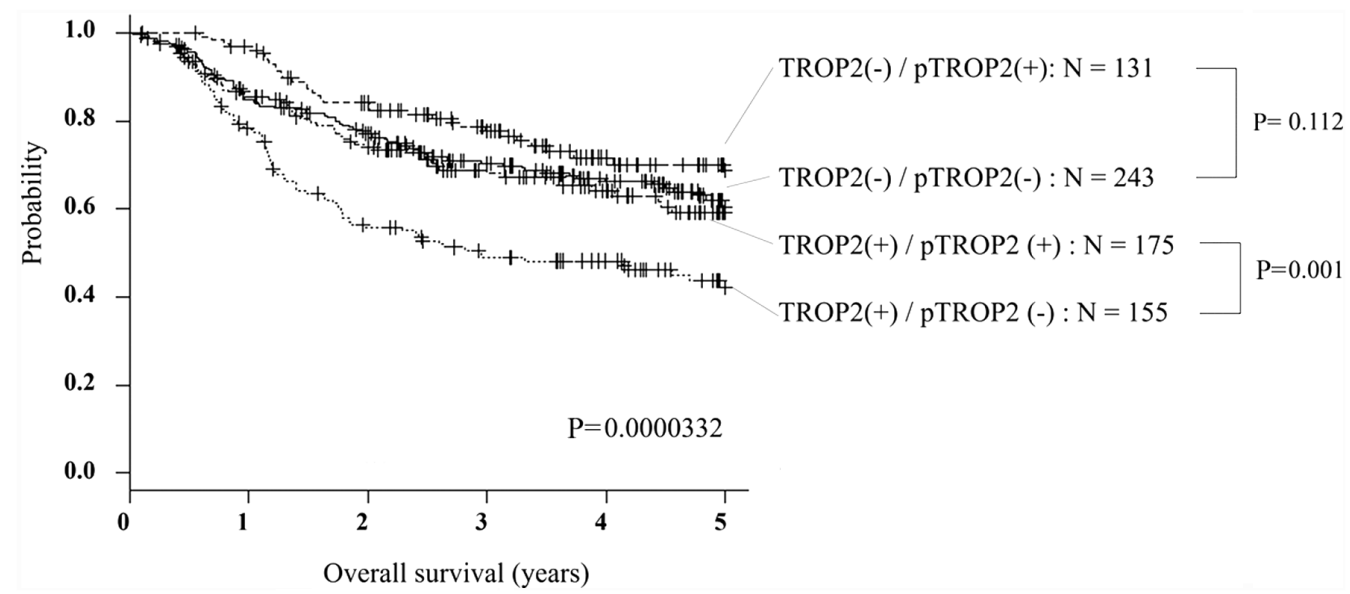

Figure 3. Kaplan-Meier survival curves of subgroup analysis according to TROP2 and pTROP2 upregulation. Patients with TROP2(-)/pTROP2(+) had a good prognosis, and patients with TROP2(+)/pTROP2(-) had a poor prognosis. TROP2(+)/pTROP2 (-) had a poorer prognosis than TROP2 (+)/pTROP2(+). (P<0.01). TROP2, trophoblast cell-surface antigen 2; pTROP2, phospho-trophoblast cell-surface antigen 2. 


\section{Discussion}

Our present analyses demonstrated that TROP2 overexpression was significantly associated with tumor depth, lymph node metastasis, and vessel invasion in GC. Stoyanova et al (20) reported that the intracellular domain of TROP2 might stimulate cyclin D1 and c-myc. TROP2 overexpression might be correlated with the progression of GC via up-regulations of cyclin D1 and c-myc. In the present patient series, the OS of the GC patients with TROP2 overexpression was poor. The univariate analysis indicated that the patients' OS was significantly correlated with TROP2, whereas the multivariate analysis demonstrated that TROP2 overexpression was not correlated with OS. These findings might indicate that TROP2's signal is associated with the progression of GC cells, and that TROP2 could be one of the predictive markers for poor survival of GC patients.

We observed herein that TROP2 overexpression was associated with the intestinal type of GC. Mühlmann et al (12) also reported that TROP2 was correlated with the histological intestinal type of GC. It has been reported that adhesion molecules such as claudins and cadherins might play an important role in the histology of cancer cells $(21,22)$. TROP2's signal up-regulates the tight junctions (which are associated with histologically intestinal type of GC), suggesting that TROP2 might be involved in the histological formation of GC.

In contrast, our analyses revealed that pTROP2 overexpression was associated with tumor depth (T1 or T2), no lymph node metastasis, and no lymphatic invasion, resulting in a good prognosis. The overexpression of pTROP2 might have tumor-suppressive functions with clinical significance that differs from that of TROP2. Fig. 3 suggests that although the prognosis is poor when TROP2 is overexpressed, phosphorylation of TROP2 has a function of reducing cancer malignancy. Sin et al (17) reported that TROP2 suppressed IGF1R and ALK signaling as a tumor-suppressing function. The mechanism of this suppression is that IGF1 and midkine bind to TROP2 and inhibit the signals of IGF1R and ALK, which play critical roles in cell growth, differentiation, transformation, and metastasis (23-25).

Mori et al (19) demonstrated that in colon cancer cells, PKC $\alpha$ and PKC $\delta$ were involved in TROP2 phosphorylation, and TROP2 phosphorylation changed the localization of claudin7 and promoted cell motility. TROP2 phosphorylation may have a suppressive effect on GC, and pTROP2 may inhibit the IGF1R and ALK signal pathway. The clinicopathologic significance of pTROP2 might differ among cancer types. Taken together, the above-described findings and our present results suggest that the phosphorylation of TROP2 may restrain tumor progression in GC.

Currently, several clinical trials using the therapeutic agents against TROP2, DS-1062 and IMMU-132, are ongoing in lung cancer (DS-1062, NCT 03401385), urothelial cancer (IMMU-132, NCT 03547973), and triple negative breast cancer (IMMU-132, NCT 04230109). It was reported that IMMU-132 had efficacy in a heavily pretreated population of patients with metastatic triple-negative breast cancer (26). Phase III study of IMMU-132 in patients with metastatic triple negative breast cancer is in progress (NCT 02574455). Our data suggest that a clinical trial using these agents might 
be useful for GC patients with TROP2 expression. In this study, we analyzed the clinicopathological features of TROP2 and pTROP2, and conclude the data as clinical significance in patients with GC. We would like to clarify the effect of TROP2 inhibitors on the proliferation of GC cell lines in vivo and in vitro in future.

In conclusion, TROP 2 might be associated with the tumor progression of GC cells, resulting in poor prognoses of patients with GC. pTROP2 might be associated with a tumor-suppressing function.

\section{Acknowledgements}

The authors would like to thank Ms. Akiko Tsuda (Department of Molecular Oncology and Therapeutics, Osaka City University Graduate School of Medicine, Osaka 545-8585, Japan) for technical support of immunohistochemistry. The abstract was presented at the Annual Meeting of the American Association for Cancer Research June 22-24 Virtual Meeting II, Sessions Available Online, 2020 and published as abstract no. 6465 in Cancer Research 80 (Supplement): 2020.

\section{Funding}

The present study was supported by Grant-in-Aid for Scientific Research (B) (grant no. 18H02883).

\section{Availability of data and materials}

The datasets used and/or analyzed during the current study are available from the corresponding author on reasonable request.

\section{Authors' contributions}

SK and MYa conceived the present study. MYo, TTa, TTo, HT, KM and MO treated the patients and collected clinical data of the patients who underwent gastrectomy. HN prepared the antibody. SK performed the experiments and analyzed them. SK and MYa confirm the authenticity of all the raw data. SK, MYa, YY, TS, AS, SN, ST and KK evaluated and interpreted the data. SK and MYa verified the analytical methods. MYa supervised the findings of this work. All authors discussed the results and contributed to the final manuscript. All authors read and approved the final manuscript.

\section{Ethics approval and consent to participate}

The present study was approved by Osaka City University Ethics Committee (reference no. 924). Informed consent was obtained in writing from all patients.

\section{Patient consent for publication}

Not applicable.

\section{Competing interests}

The authors declare that they have no competing interests.

\section{References}

1. Global Burden of Disease Cancer Collaboration, Fitzmaurice C, Allen C, Barber RM, Barregard L, Bhutta ZA, Brenner H, Dicker DJ, Chimed-Orchir O, Dandona R, et al: Global, regional, and national cancer incidence, mortality, years of life lost, years lived with disability, and disability-adjusted life-years for 32 cancer groups, 1990 to 2015: A systematic analysis for the global burden of disease study. JAMA Oncol 3: 524-548, 2017.

2. Fornaro L, Vasile E, Aprile G, Goetze TO, Vivaldi C, Falcone A and Al-Batran SE: Locally advanced gastro-oesophageal cancer: Recent therapeutic advances and research directions. Cancer Treat Rev 69: 90-100, 2018.

3. Gambardella V and Cervantes A: Precision medicine in the adjuvant treatment of gastric cancer. Lancet Oncol 19: 583-584, 2018.

4. Wanger TM, Dewitt S, Collins A, Maitland NJ, Poghosyan Z and Knauper V: Differential regulation of TROP2 release by PKC isoforms through vesicles and ADAM17. Cell Signal 27: 1325-1335, 2015

5. Cubas R, Li M, Chen C and Yao Q: Trop2: A possible therapeutic target for late stage epithelial carcinomas. Biochim Biophys Acta 1796: 309-314, 2009.

6. Vidmar T,Pavsic M and Lenarcic B: Biochemical and preliminary X-ray characterization of the tumor-associated calcium signal transducer 2 (Trop2) ectodomain. Protein Expr Purif 91: 69-76, 2013.

7. Huang H, Groth J, Sossey-Alaoui K, Hawthorn L, Beall S and Geradts J: Aberrant expression of novel and previously described cell membrane markers in human breast cancer cell lines and tumors. Clin Cancer Res 11: 4357-4364, 2005.

8. Shvartsur A and Bonavida B: Trop2 and its overexpression in cancers: Regulation and clinical/therapeutic implications. Genes Cancer 6: 84-105, 2015.

9. Guerra E, Trerotola M, Dell' Arciprete R, Bonasera V, Palombo B, El-Sewedy T, Ciccimarra T, Crescenzi C, Lorenzini F, Rossi C, et al: A bicistronic CYCLIN D1-TROP2 mRNA chimera demonstrates a novel oncogenic mechanism in human cancer. Cancer Res 68: 8113-8121, 2008.

10. Lin JC, Wu YY, Wu JY, Lin TC, Wu CT, Chang YL, Jou YS, Hong TM and Yang PC: TROP2 is epigenetically inactivated and modulates IGF-1R signalling in lung adenocarcinoma. EMBO Mol Med 4: 472-485, 2012.

11. Zhao W, Zhu H, Zhang S, Yong H, Wang W, Zhou Y, Wang B, Wen J, Qiu Z, Ding G, et al: Trop2 is overexpressed in gastric cancer and predicts poor prognosis. Oncotarget 7: 6136-6145, 2016.

12. Mühlmann G, Spizzo G, Gostner J, Zitt M, Maier H, Moser P, Gastl G, Zitt M, Müller HM, Margreiter R, et al: TROP2 expression as prognostic marker for gastric carcinoma. J Clin Pathol 62: 152-158, 2009.

13. Fong D, Moser P, Krammel C, Gostner JM, Margreiter R, Mitterer M, Gastl G and Spizzo G: High expression of TROP2 correlates with poor prognosis in pancreatic cancer. Br J Cancer 99: 1290-1295, 2008.

14. Fong D, Spizzo G, Gostner JM, Gastl G, Moser P, Krammel C, Gerhard S, Rasse M and Laimer K: TROP2: A novel prognostic marker in squamous cell carcinoma of the oral cavity. Mod Pathol 21: 186-191, 2008.

15. Fang YJ, Lu ZH, Wang GQ, Pan ZZ, Zhou ZW, Yun JP, Zhang MF and Wan DS: Elevated expressions of MMP7, TROP2, and survivin are associated with survival, disease recurrence, and liver metastasis of colon cancer. Int J Colorectal Dis 24: 875-884, 2009.

16. Bignotti E, Todeschini P, Calza S, Falchetti M, Ravanini M, Tassi RA, Ravaggi A, Bandiera E, Romani C, Zanotti L, et al: Trop-2 overexpression as an independent marker for poor overall survival in ovarian carcinoma patients. Eur J Cancer 46: 944-953, 2010.

17. Sin STK, Li Y, Liu M, Ma S and Guan XY: TROP-2 exhibits tumor suppressive functions in cervical cancer by dual inhibition of IGF-1R and ALK signaling. Gynecol Oncol 152: 185-193, 2019.

18. Zhang K, Jones L, Lim S, Maher CA, Adkins D, Lewis J, Kimple RJ, Fertig EJ, Chung CH, Van Tine BA, et al: Loss of Trop2 causes ErbB3 activation through a neuregulin-1-dependent mechanism in the mesenchymal subtype of HNSCC. Oncotarget 5: 9281-9294, 2014. 
19. Mori Y, Akita K, Ojima K, Iwamoto S, Yamashita T, Morii E and Nakada H: Trophoblast cell surface antigen 2 (Trop-2) phosphorylation by protein kinase $\mathrm{C} \alpha / \delta(\mathrm{PKC} \alpha / \delta$ ) enhances cell motility. J Biol Chem 294: 11513-11524, 2019.

20. Stoyanova T, Goldstein AS, Cai H, Drake JM, Huang J and Witte ON: Regulated proteolysis of Trop2 drives epithelial hyperplasia and stem cell self-renewal via $\beta$-catenin signaling. Genes Dev 26: 2271-2285, 2012.

21. Soini Y, Tommola S, Helin H and Martikainen P: Claudins 1, 3, 4 and 5 in gastric carcinoma, loss of claudin expression associates with the diffuse subtype. Virchows Arch 448: 52-58, 2006.

22. Stanculescu D, Margaritescu C,Stepan A and Mitrut AO: E-cadherin in gastric carcinomas related to histological prognostic parameters. Rom J Morphol Embryol 52 (Suppl 3): S1107-S1112, 2011.

23. Larsson O, Girnita A and Girnita L: Role of insulin-like growth factor 1 receptor signalling in cancer. Br J Cancer 92: 2097-2101, 2005 .
24. Rosenzweig SA and Atreya HS: Defining the pathway to insulin-like growth factor system targeting in cancer. Biochem Pharmacol 80: 1115-1124, 2010.

25. Chiarle R, Voena C, Ambrogio C, Piva R and Inghirami G: The anaplastic lymphoma kinase in the pathogenesis of cancer. Nat Rev Cancer 8: 11-23, 2008.

26. Bardia A, Mayer IA, Vahdat LT, Tolaney SM, Isakoff SJ, Diamond JR, O'Shaughnessy J, Moroose RL, Santin AD, Abramson VG, et al: Sacituzumab govitecan-hziy in refractory metastatic triple-negative breast cancer. N Engl J Med 380: 741-751, 2019.

This work is licensed under a Creative Commons Attribution-NonCommercial-NoDerivatives 4.0 International (CC BY-NC-ND 4.0) License. 